\title{
Routes of Transmission 2019-nCoV and Optometry Practice
}

\author{
Raj Kumar* \\ Department of Optometry, Chandigarh University, Mohali, Punjab-140413, India
}

"Email: optomrajlvpei@gmail.com

\section{ARTICLE INFORMATION}

Received: April 04, 2020

Revised: July 08,2020

Accepted: July 13, 2020

Published Online: July 30, 2020

\section{Keywords:}

A novel $\beta$-coronavirus (2019-nCoV), optometry practice, eye care professional, droplet, inhalation transmission

\begin{abstract}
A novel $\beta$-coronavirus (2019 novel coronavirus) affected severe as well to uniform fetal pneumonia, traveled through a seafood bazaar of Wuhan town, Hubei region, China, also quickly extent toward excess boonies of China and more nations. The 2019-nCoV existed dissimilar after SARS-CoV, then cooperative the similar crowd receptor the social ACE2 (angiotensin-converting enzyme2). The regular crowd of 2019 novel coronavirus could conventional continue bat Rhinolophusaffin is a 2019 novel coronavirus presented $96.2 \%$ of entire-genome character toward BatCoV RaTG13. The person-to-person spread methods of 2019-nCoV involved tool, identical cough, sneeze droplet inhalation transmission, and obtain in-tuned with transmission, just like the interaction by way of oral, nasal, as well as eye mucous films. 2019-nCoV container too exist spread over the saliva, also thus the fetal-oral ways similarly can remain a possible person-to-person spread mode. The observers now optometry run through representation just before the incredible danger of 2019$\mathrm{nCoV}$ contagion because of the face-to-face announcement too thus the expose en route for tears, plasma, plus additional body liquids, besides therefore the diagnostic and treatment of apparatuses. Eye care professional perform inordinate heroes in stopping the spread of 2019-nCoV. At this time we indorse the contagion control actions all through optometry exercise just before block the person-to-person spread ways in eye care health center as well as hospitals.
\end{abstract}

\section{Introduction}

A developing pneumonia epidemic instigated in Wuhan Town, within the getting on December 2019 (Zhu et al., 2020). The pneumonia contamination makes sure a fast extent beginning Wuhan route for utmost additional outlying areas as well as new 24 countries (Wang et al., 2020; Liu et al., 2020). WHO acknowledged the community healthiness disaster of global alarm above this worldwide pneumonia epidemic continuously Jan 30, 2020.

The classic medical indications of patients who writhed starting the novel viral infection occurred temperature, cough, in addition, myalgia or tiredness through unusual rib cage CT, then, therefore, the smaller amount communal indicators existed sputum production, annoyance, hemoptysis, as well as diarrhea (Huang et al., 2020; Guan et al., 2020; Wang et al., 2020). This novel infective cause is additionally possible in the direction of upset older fellows to source undecorated breathing diseases (Chen et al., 2020; Chan et al., 2020) an amount of the scientific indications be situated dissimilar after the severe grim lung disorder (SARS) produced by SARS coronavirus (SARS-CoV) that come to pass in 2002-2003, demonstrating that an additional person-to-person communication virulent go-between has produced this developing virus-related infection outbreak (Chen et al., 2020; Li et al., 2020). The infective representative of this viral contamination bang up-to-date in Wuhan existed as a final point known in place of a totally irreplaceable coronavirus (2019 novel coronavirus), the seventh associate of the household of coronaviruses that contaminate humans (Zhou et al., 2020). Taking place $11^{\text {th }}$ February 2020, World Health Organization called the novel viral contagion according to "Corona Virus Disease (COVID19)", however, the ICTV (International Committee on Taxonomy of Viruses) recommended this novel coronavirus designation such in place of "SARSCoV-2" thanks a lot toward the phylogenetic and taxonomic examination of this novel coronavirus.

\section{Features of 2019-nCoV}

Presently, nearby stand four types of coronaviruses: $\alpha-\mathrm{CoV}$, $\beta$ - $\mathrm{CoV}, \gamma-\mathrm{CoV}$, and $\delta$ - $\mathrm{CoV}$ (Nakagawa, Lokugamage, \& Makino, 2016; Fan, Zhao, Shi, \& Zhou, 2019). Record of the 
coronavirus container reason the transmittable infections in anthropological besides vertebrates. The $\alpha-\mathrm{CoV}$ and $\beta-\mathrm{CoV}$ primarily poison the breathing, abdominal, and central nervous system of human being and living thing, despite the fact $\gamma-\mathrm{CoV}$ and $\delta-\mathrm{CoV}$ generally communicate a disease to the birds (Fehr \& Perlman 2016; Perlman \& Netland 2009; Weiss \& Leibowitz 2011; Yin \& Wunderink, 2018). Regularly, quite a few associates of the coronavirus reason mild breathing infection in individuals; conversely, SARS$\mathrm{CoV}$ then thus the Mid-East breathing disease coronavirus (MERS-CoV) discovered in 2002-2003 also in 2012, correspondingly, produced disastrous spartan breathing diseases (Holmes, 2003; Falsey \& Walsh, 2003; The Lancet, 2013). The SARS-CoV besides MERS-CoV is in the right place near the $\beta$-CoV (Al-Tawfiq, Zumla, \& Memish, 2014; Song et al., 2019). 2019-nCoV discovered in Wuhan similarly be in the right place toward the $\beta-\mathrm{CoV}$ dependable with the phylogenetic examination maintained the viral genome (Wu et al., 2020; Zhou et al., 2020). Even though the nucleotide arrangement relationship is a smaller amount of important expanse than $80 \%$ among $2019-\mathrm{nCoV}$ in addition to SARS$\mathrm{CoV}$ (around 79\%) or MERS-CoV (around 50\%), 2019$\mathrm{nCoV}$ similarly dismisses reason the fetal contagion also extent further later than the double additional coronaviruses (Chen et al.,2020; Li et al., 2020; Zhou et al., 2020; De Wit et al., 2016; Al-Tawfiq et al., 2014; Bai, Nie, \& Wen, 2020). The genome nucleotide structure individuality among a coronavirus (BatCoV RaTG13) identified inside the bat Rhinolophu saffinis is beginning Yunnan, China, also $2019-\mathrm{nCoV}$, existed $96.2 \%$, representative that the expected multitude of 2019-nCoV possibly will similarly remain present the Rhinolophu saffinis bat (Zhou et al., 2020). On the other hand, the alterations may well similarly recommend that there's or additional isolating hosts in the middle of the bat and humanoid. An examination team beginning the South China Agricultural University obligates devoted relatively 1000 seen genomic trials beginning pangolins, and positioned that $70 \%$ pangolins controlled $\beta$-CoV28. Representative that the pangolin possibly will well similarly remain the host of 2019-nCoV (Wahba et al., 2020).

2019-nCoV overcome the ordinary coronavirus construction using "spike protein" inside the tissue envelope ( $\mathrm{Li}, 2016)$, as well as similarly communicated extra poly-proteins, nucleoprotein and also membrane proteins, similar RNA polymerase, 3-chymotrypsin-like protease, papain-like protease, helicase, glycoprotein, also attachment proteins (Wu et al., 2020; Wu et al., 2020; $\mathrm{Li}, 2016)$. The $\mathrm{S}$ protein beginning coronavirus dismisses quandary toward the receptors of the crowd to expedite viral admission obsessed by mark cells (Hantak et al., 2019; Belouzard et al., 2012). Even though in attendance remain four amino-alkanoic acid variations of $S$ protein among 2019-nCoV as well as above SARS-CoV, 2019$\mathrm{nCoV}$ furthermore container quandary just before the humanoid angiotensin changing enzyme 2 (ACE2), a correspondent host receptor used on behalf of SARS-CoV, for example, 2019-nCoV container predicament to the ACE2 receptor as of the cells beginning humanoid, bat, pig, and civet cat. Then again the situation terminates predicament in the direction of the cells devoid of ACE2 (Zhou et al., 2020; Wan et al., 2020; Chai et al., 2020; Fan et al., 2020). A recombinant ACE2-Ig antibody, a SARSCoVparticular humanoid antibody, besides consequently the serum preliminary a convalescing SARS-CoV-infected persistent, which may possibly deactivate $2019-\mathrm{nCoV}$, complete ACE2 for the multitude receptor in lieu of 2019nCoV (Hoffmann et al., 2020; Huang, \& Herrmann, 2020; Lei et al., 2020; Tian et al., 2020). The extraordinary empathy among ACE2 also 2019-nCoV S protein moreover submitted that the people using advanced appearance of ACE2 may well remain extra in danger toward 2019-nCoV (Zhao et al., 2020; Guy et al., 2005).

\section{The Feasible Communication Methods of 2019 Novel Coronavirus}

The collective spread paths of 2019-nCoV comprise spread contrivance (cough, sneeze droplet, breathing spread) besides contract in touch by spread (exchange by oral, nasal, and eye mucous tissues) (Lu et al., 2020). Though mutual medical expressions of novel coronavirus contamination don't take account of eye indicators, the investigation of conjunctival examples from complete and supposed circumstances of 2019-nCoV put it to somebody that the communication of 2019-nCoV isn't inadequate to the breathing tract (Huang et al., 2020), which judgment introduction may perhaps be responsible for an active mode on behalf of the disease to enter the body (To et al., 2020).

Now adding, educations and awareness require that exposed infections be present frequently transferred starting person to person, unintended interaction, complete granular or minor precipitations, in addition to 2019-nCoV. Similarly canister be pass on nonstop or secondarily concluded saliva (Belser, Rota, \& Tumpey, 2013). Coronaviruses are appropriate towards the person of Coronaviridae, of the direction Nidovirales, consist of enormous, particular, plusstranded RNA by way of their genome (Fehr \& Perlman, 2015; Gorbalenya et al., 2006). At present, there exist four types of coronaviruses: $\alpha-\mathrm{CoV}, \beta-\mathrm{CoV}, \gamma-\mathrm{CoV}$, plus $\delta-\mathrm{CoV}$ (Rothe et al., 2020).

Revisions be necessary advised that 2019-nCoV may well similarly be flying done vaporizers designed for 
the period of medicinal procedures (Wax \& Christian, 2020). It's outstanding that 2019-nCoV RNA may perhaps smooth be there noticed in rRT-PCR difficult for the duration of a stool sample composed on day 7 of the patient's illness (Holshue et al., 2020). On the other hand, the vaporizer conduction way and consequently the fecaloral communication way apprehensive by the broadspectrum community still got to be additionally calculated and established.

\section{Feasible Communication Ways of 2019-nCoV in Optometry Clinics}

From the time when 2019-nCoV be present frequently accepted straight from person to person through the tract, droplets, developing suggestions recommended that the situation may perhaps also be communicated finished communication and fomites (To et al., 2020; Rodriguez-Morales et al., 2020). Moreover, the asymptomatic while retro for persons infested with 2019-nCoV obligates be present recounted to be $\sim 1-$ 14 days, and after 24 days personages were informed, and it consumed been long-established that persons devoid of indications container extent the virus (Huang et al., 2020; Guan et al., 2020; Backer, Klinkenberg, \& Wallinga, 2020). To et al. informed that aware viruses be situated existent outside the saliva of infected persons through virus-related principles method (To et al., 2020). Likewise, it's presently established that 2019-nCoV move in the cell inside a similar route by way of SARS coronavirus, that is, finished the ACE2 cell receptor (De Wit et al., 2016). 2019 novel coronavirus dismiss successfully consumption ACE2 for example a receptor to attack cells, which possibly will stimulate human-tohuman spread (Zhou et al., 2020). ACE2+ cells existed originally chosen plentifully current during the course of the zone, also for the reason that the cells morphologically companionable by vessel gland tube epithelium in the humanoid oral cavity. ACE2+ epithelial cells of saliva gland ducts are present confirmed to be a type primary objectives of SARSCoV infection (Liu et al., 2011), also $2019-\mathrm{nCoV}$ is perhaps accepted to be an equal state of affairs, though not any investigation make sure be situated informed consequently far-off.

Ophthalmic patients and professionals are often wideopen to pathogenic diseases, as well as viruses and bacteria that communicate a disease to the mouth and expanse. Optometry care backgrounds regularly transfer the threat of 2019-nCoV contamination thanks a lot to the specificity of the situation techniques, which consist of face-to-face messages through patients, then regular contact toward tears, plasma, plus additional fluid physique material's, also as a result the management of devices. The pathogenic germs are situated repeatedly pass on in optometry areas over and done with a mouthful of air of airborne germs which backbone continue postponed in the interior the appearance for extensive periods (Kampf et al., 2020), through the exchange by plasma, interaction, or additional persistent materials (Chen, 2020), the interaction of conjunctival, nasal, or oral cavity through droplets besides aerosols enclosing microbes produced starting septic separate besides thrust a fleeting remoteness through coughing plus speaking lacking a mask (Cleveland et al., 2016; Harrel \& Molinari, 2004), in addition to secondary exchange by dirtied appliances plus/before environmentally friendly surfaces (Liu et al., 2011). Contagions powerfulness be situated current done at all of those disorders difficult in an infested singular in the optometry health center and hospitals, particularly for the duration of the epidemic of 2019-nCoV.

\section{Above Ground Spread}

The free extent of SARS-Cov (severe serious breathing syndrome-Cov) is reported popular several non-fiction. Therefore, droplet and atomizer communication of 2019$\mathrm{nCoV}$ be there the principal significant fears in the optometry health centers and hospitals, as it's rigid in the direction of eluding the peers of huge volumes of aerosol and droplet diverse thru patient's saliva besides even blood during ophthalmic practice (Cleveland et al., 2016). Additionally to the infested patient's cough and breathing, optometry campaigns like direct ophthalmoscopy and retinoscopy. Subdivisions of droplets and aerosols remain adequately trivial on the way to continue airborne used for a prolonged pass previously they indicate environmentally friendly exteriors or pass in the expanse. Consequently, the 2019$\mathrm{nCoV}$ requires the prospective to extent concluded evening dew and atomizers beginning infested persons in optometry private clinics and hospitals.

\section{Communication Spread}

An optometry professional's recurrent straight or secondary interaction by enduring resources also adulterated optometry apparatuses or conservational planes types a probable way to the extent of viruses (Cleveland et al., 2016). Additionally, an optometrist besides extra patients obligate possible interaction of conjunctival, adenoidal, or oral with droplets enclosing viruses produced as of a disease-ridden separate in addition impelled a momentary space by coughing and conversation lacking a facade. In effect contagion regulator stratagems are necessary to break the extent of $2019-\mathrm{nCoV}$ over and done with these interaction sequences. 


\section{Infected Outer Surface Spread}

Humanoid coronaviruses identical SARS-CoV, Middle East Breathing Condition coronavirus (MERS-CoV), before prevalent humanoid coronaviruses $(\mathrm{HCoV})$ container, keep it up on planes similar metallic, lead crystal, or elastic for up to an insufficient of days (Kampf et al., 2020; Otter et al., 2016). As a result, adulterated exteriors that be present regularly communicated in health care situations remain a promising foundation of coronavirus communication. Rehearses resulting drops and tears on or after healthy patients, which probably infect the intact superficial in optometry workplaces. Additionally, it existed given away at the infection that $\mathrm{HCoV}$ remnants communicable after two hours up to nine days, also keep it up to improved at $50 \%$ associated with a $30 \%$ share. As a result, protecting a hygienic and waterless atmosphere inside the optometry place of work long for benefit reduction the perseverance of 2019-nCoV.

\section{Infection Controls in Place of Optometry Practice}

Optometrist have to be aware in what way $2019-\mathrm{nCoV}$ is the extent, the method to recognize patients by way of 2019-nCoV contamination, plus anything extra-protective processes had better is accepted for the duration of the practice, thus by way of to discontinue the communication of 2019-nCoV. At this time be present praise the contamination resistor processes that have to be monitored by an optometrist, for the most part because of the very fact that breath transmission also droplets be present measured for the key feast ways of 2019-nCoV.

\section{Patient Assessment}

Optometrist must be ready on the way to recognize a doubted circumstance of COVID-19. Usually a patient having COVID-19, who is the serious feverish stage of the infection isn't suggested toward the optometry clinic. The uncertainty this prepares happen, the optometrist have a duty to be prepared to isolate the patient through doubted 2019-nCoV infection, in addition to will not treat the patient trendy the optometry treatment center, but then again instantly isolation the patient also reports to the infection regulator division as per rapidly as likely, above all inside the epidemic epoch of 2019 novel coronavirus.

The fever patient must remain leisurely in at first domicile. A contact-free forehead thermometer is intensely suggested on behalf of the screening. A feedback form have to remain rummage-sale to curtain patients by possible contamination of 2019-nCoV earlier they might remain commanded in the direction of the optometry chairside. These answers must take account of the following:

(1) Does have temperature or knowledge infection surrounded by the historical 14 days?

(2) Require you ever qualified a fresh beginning of breathing difficulties, similar a cough or trouble in inhalation inside the previous 14 days?

(3) Require you ever, surrounded thru the earlier 14 days, and journeyed toward Wuhan town plus its nearby zones, or go to the quarter thru recognized 2019-nCoV spread?

(4) Have you inherit interaction by a patient thru set 2019$\mathrm{nCoV}$ contamination in the earlier 14 days?

(5) Have you ever get communication thru people that originate as of Wuhan city also its contiguous parts, otherwise persons after the zone by current recognized temperature or breathing difficulties in the previous 14 days?

(6) Are around a least of two persons by recognized involvement of fever or breathing difficulties contained by the previous 14 days make sure near interaction thru you?

(7) Have you ever in recent times contributed in any get-together, conferences, otherwise taken nearby interaction thru various unaware persons.

Condition a patient answers "yes" to some of the airing queries, also his/her fever is less $37.3{ }^{\circ} \mathrm{C}$, the optometrist can accept the management till 14 days afterward the acquaintance incident. The patient has a duty in the direction of being inculcated to the self-quarantine reaction in addition to reporting some fever practice or flu-like pattern in the direction of the native health section. Condition a patient answers "yes" in the direction of any of the showing answers, plus his/her fever is not any but $37.3{ }^{\circ} \mathrm{C}$, the patient has a duty to be closely isolated, in addition to as a result the optometrist should report back toward the contamination control section of the hospital before the native healthiness division.

Condition a patient answers "no" towards all or some the showing queries, plus his/her body heats under $37.3^{\circ} \mathrm{C}$, the optometrist can treat the patient thru additional safeguard processes, in addition to evades close processes to the pretentious.

If a patient answers "no" to all or any the showing queries, then his/her fever is not less than $37.3{ }^{\circ} \mathrm{C}$, the patient must remain educated toward the infection clinics or exceptional health center for COVID-19 on behalf of additional medicinal assistance. 


\section{Hand Sanitization}

Fecal-oral communication obligates to be located informed for 2019-nCoV, which emphasizes the character of hand sanitation in place of optometry practice. While suitable hand sanitation is that the monotonous precondition for optometry practice, hand-washing compliance is reasonably low, which levies an exceptional task to the contamination resistor in the epidemic period of 2019$\mathrm{nCoV}$ communication. Strengthening forever hand sanitation is of paramount significance. Toward make stronger the acquiescence of hand wash. Especially, the health specialists have to wash their hands earlier patient going-over, earlier optometry processes, after moving the patient, afterward moving the surrounds plus apparatus devoid of sterilization, also afterward touching the oral cavity, injured skin or wound, blood, body liquid, discharge, plus excreta. Added attention has to be engaged used for the optometry specialists to evade touching their individual eyes, mouth, and nose.

\section{Individual Defensive Actions Intended for the Optometry Consultants}

Next to current, there's definitely not an unambiguous recommendation for the safety of optometrist as of 2019$\mathrm{nCoV}$ contamination within the optometry health center and hospitals. While not at all optometrist has been recounted to accrue 2019-nCoV contamination in the direction of the time of paper existed drafted, the previous involvement by the SARS coronavirus ensures exposed massive amounts of picked up contamination of health specialists in hospital settings (Seto et al., 2003). Breathing droplet communication of contamination is occupied into a justification for the chief way of extent, mostly in health care center also hospitals, barrier-protection kit, counting protecting eyewear, facades, gloves, caps, face guards, in addition to defensive outwear, is muscularly mentioned in place of all health care benefactors inside the clinic/hospital surroundings for the period of the epidemic retro of 2019 novel coronavirus.

Generated arranged the probability of the extent of 2019 novel coronavirus contamination, three-level defensive actions of the optometry specialists exist suggested on behalf of precise circumstances. (1) Primary safeguard (regular defense in lieu of workforces in clinical situations). Wearing a one-use working cap, reusable medical mask, also dealing dresses (white coat), with safety glasses or face safeguard, plus reusable rubber gloves or else nitrile gloves essential. (2) Secondary safeguard (progressive safety in lieu of optometry specialists). Wearing one-use doctor cap, one-use medical mask, protecting safety glasses, face protection, plus dealing garments (white coat) with one-use separation dress or medical clothes outside, also one-use rubber gloves. (3) Tertiary safeguard (fortified defense while contact patient thru supposed or else confirmed 2019-nCoV contamination). While a patient through 2019-nCoV contamination isn't predictable to be treated inside the optometry health center, If inside the unlikely happening, therefore, the optometry specialized dismiss elude close interaction, special defensive outwear is compulsory. Uncertainty defensive outwear isn't accessible, in work clothes (white coat) through an additional one-use defensive dress external must be worn.

\section{Slit-lamp Breath Shield}

The usage of a slit lamp breath shield can meaningfully reduce the assembly of saliva plus droplet or shower, mainly in bags once slit-lamp examination. It's been reported that the utilization of a slit lamp breath shield could significantly reduce airborne particles in - 7.5" Long X 5.5" Wide. The implementation of an entire slit lamp breathe shields necessary. If slit lamp breath shields impossible in some cases, other devices, like indirect ophthalmoscopy and torchlight, are recommended for examination of the posterior and anterior segment of the eye, to attenuate the generation of droplet inhalation transmissions very much like possible.

\section{Sterilization of the Clinic Sites}

Health organizations must take real and stringent decontamination methods in together clinic locations plus community zone. The clinic locations must be cleaned also sanitized. Besides applications should uniform be regularly scrubbed and sanitized, as well as door grips, chairs, and counters. The elevator should be sanitized frequently. Individuals compelling elevators must wear façades appropriately and avoid undeviating interaction with switches and other substances.

\section{Supervision of Medical Waste}

The medicinal waste (as well as one-use defensive kit once usage) would be conveyed toward the transitory cargo zone of the medicinal institution well-timed. The environmentally friendly tool plus substances have to exist pretreated, washed, treated, and also correctly deposited in conflict through the protocol. The medicinal plus home discarded produced by the management of patients by assumed or complete 2019-nCoV contamination are measured communicable 
medicinal excess. Double-layer yellow shade health excess package baggage plus "gooseneck" ligation must be used. The appearance of the suite bags must be noticeable plus predisposed regular with the essential on behalf of the organization of medicinal waste.

\section{Summary}

As of December 2019, the recently exposed coronavirus (2019 novel coronavirus) obligates produced the epidemic of pneumonia in Wuhan in addition to after also all over the world. 2019 novel coronavirus arrives host cells complete humanoid cell receptor ACE2, a corresponding by SARS-CoV, however then again through progressive compulsory affinity (Wrapp et al., 2020). The quickly accumulative digit of cases plus confirmation of humanto-human communication recommended that the virus existed additionally communicable than SARS-CoV and MERS-CoV9, (De Wit et al., 2016; Bai et al., 2020; Wrapp et al., 2020). Through middle-Feb 2020, an enormous digit of contaminations medicinal workforce are reported (The Novel Coronavirus Pneumonia Emergency Response Epidemiology Team, 2020), besides consequently the particular causes instead of the miscarriage of safety became to remain encouraged reconnoitered. Even though health centers like stomatology is locked for the duration of the endemic, an oversized digit of alternative patients quiet be present at the optometry health center and hospitals in place of management. We've précised the conceivable communication ways of $2019-\mathrm{nCoV}$ popular stomatology, comparable the flying extent, communication extent, and adulterated superficial spread. We furthermore go through several detailed practical guidelines toward obstruction infection spread in the direction of source a situation on behalf of stopping the communication of 2019 novel coronavirus for the duration of optometry diagnosis and treatment, as well as patient evaluation, hand sanitation, individual protecting actions for the optometry specialists.

\section{References}

Al-Tawfiq, J. A., Zumla, A. \& Memish, Z. A. (2014). Coronaviruses: Severe acute respiratory syndrome coronavirus and Middle East respiratory syndrome coronavirus in travelers. Curr. Opin. Infect. Dis. 27(5), 411-417. https://doi.org/10.1097/QCO.0000000000000089

Backer, J. A., Klinkenberg, D. \& Wallinga, J. (2020). Incubation period of 2019 novel coronavirus (2019$\mathrm{nCoV}$ ) infections among travellers from Wuhan, China, 20-28 January 2020. Euro. Surveill., 25(5), 1-6.
https://doi.org/10.2807/1560-7917.ES.2020.25.5. 2000062

Bai, Y., Nie, X. \& Wen, C. (2020). Epidemic prediction of 2019-nCoV in Hubei province and comparison with SARS in Guangdong province. The lancet. Available at SSRN:

https://papers.ssrn.com/sol3/papers.cfm?abstract_ $\mathrm{id}=3531427$

Belouzard, S., Millet, J. K., Licitra, B. N. \& Whittaker, G. R. (2012). Mechanisms of coronavirus cell entry mediated by the viral spike protein. Viruses, 4(6), 1011-1033. https://doi.org/10.3390/v4061011

Belser, J. A., Rota, P. A. \& Tumpey, T. M. (2013). Ocular tropism of respiratory viruses. Microbiol. Mol. Biol. Rev., 77(1), 144-156.

https://doi.org/10.1128/MMBR.00058-12

Chai, X. et al. (2020). Specific ACE2 expression in cholangiocytes may cause liver damage after 2019$\mathrm{nCoV}$ infection. Preprint at

https://www.biorxiv.org/content/10.1101/2020.02.03 $.931766 \mathrm{v} 1$

Cleveland, J. L. et al. (2016). Transmission of blood-borne pathogens in US dental healthcare settings: 2016 update. J. Am. Dent. Assoc. 147(9), 729-738.

https://doi.org/10.1016/j.adaj.2016.03.020

Chen, J. (2020). Pathogenicity and transmissibility of 2019-nCoV—a quick overview and comparison with other emerging viruses. Microb. Infect., 22(2), 69-71. https://doi.org/10.1016/j.micinf.2020.01.004

Chan, J. F. W. et al. (2020). A familial cluster of pneumonia associated with the 2019novel coronavirus indicating person-to-person transmission: a study of a family cluster. Lancet, 395 (10223), 514-523.

https://doi.org/10.1016/S0140-6736(20)30154-9

Chen, N. et al. (2020). Epidemiological and clinical characteristics of 99 cases of 2019novel coronavirus pneumonia in Wuhan, China: a descriptive study. Lancet 395, 507-513. https://doi.org/10.1016/S0140-6736(20)30211-7

De Wit, E., Van Doremalen, N., Falzarano, D. \& Munster, V. J. (2016). SARS and MERS: recent insights into emerging coronaviruses. Nat. Rev. Microbiol., 14, 523-534.

https://doi.org/10.1038/nrmicro.2016.81

Falsey, A. R. \& Walsh, E. E. (2003). Novel coronavirus and severe acute respiratory syndrome. Lancet, 361(9366), 1312-1313.

https://doi.org/10.1016/S0140-6736(03)13084-X 
Fan, C., Li, K., Ding, Y., Lu, W. L. \& Wang, J. (2020). ACE2 expression in kidney and testis may cause kidney and testis damage after 2019-nCoV infection. Preprint at https://www.medrxiv.org/content/10.1101/2020.02.1 $2.20022418 \mathrm{v} 1$

Fan, Y., Zhao, K., Shi, Z. L. \& Zhou, P. (2019). Bat coronaviruses in China. Viruses, 11(3), 210. https://doi.org/10.3390/v11030210

Fehr, A. R. \& Perlman, S. (2015). Coronaviruses: an overview of their replication and pathogenesis. Methods Mol. Biol., 1282, 1-23. https://doi.org/10.1007/978-1-4939-2438-7_1

Gorbalenya, A. E. et al. (2020). Severe acute respiratory syndrome-related coronavirus: The species and its viruses—a statement of the Coronavirus Study Group. Preprint at

https://www.biorxiv.org/content/10.1101/2020.02.07 $.937862 \mathrm{v} 1$

Gorbalenya, A., Enjuanes, L., Ziebuhr, J. \& Snijder, E. (2006). Nidovirales: evolving the largest RNA virus genome. Virus Res. 117(1), 17-37. https://doi.org/10.1016/j.virusres.2006.01.017

Guan, W. J. et al. (2020). Clinical characteristics of 2019 novel coronavirus infection in China. Preprint at https://www.medrxiv.org/content/10.1101/2020.02.0 $6.20020974 \mathrm{v} 1$

Guy, J. L., Lambert, D. W., Warner, F. J., Hooper, N. M. \& Turner, A. J. (2005). Membrane associated zinc peptidase families: comparing ACE and ACE2. Biochim. Biophysi. Acta 1751(1), 2-8. https://doi.org/10.1016/j.bbapap.2004.10.010

Hantak, M. P., Qing, E., Earnest, J. T. \& Gallagher, T. (2019). Tetraspanins: architects of viralentry and exit platforms. J. Virol., 93(6), 1-8.

https://doi.org/10.1128/JVI.01429-17

Harrel, S. K. \& Molinari, J. (2004). Aerosols and splatter in dentistry: a brief review of the literature and infection control implications. J. Am. Dent. Assoc., 135(4), 429-437.

https://doi.org/10.14219/jada.archive.2004.0207

Hoffmann, M. et al. (2020). The novel coronavirus 2019 (2019-nCoV) uses the SARS coronavirus receptor ACE2 and the cellular protease TMPRSS2 for entry into target cells. Preprint at

https://www.biorxiv.org/content/10.1101/2020.01.31 $.929042 v 1$. full

Holmes, K. V. (2003). SARS-associated coronavirus. $N$. Engl. J. Med., 348, 1948-1951.

https://doi.org/10.1056/NEJMp030078
Holshue, M. L. et al. (2020). First Case of 2019 Novel coronavirus in the United States. N. Engl. J. Med. 382, 929-936. https://doi.org/10.1056/NEJMoa2001191

Huang, Q. \& Herrmann, A. (2020). Fast assessment of human receptor-binding capability of 2019 novel coronavirus (2019-nCoV). Preprint at https://www.biorxiv.org/content/10.1101/2020.02.01 $.930537 \mathrm{v} 1$

Huang, C. et al. (2020). Clinical features of patients infected with 2019 novel coronavirusin Wuhan, China. Lancet, 395, 497-506.

https://doi.org/10.1016/S0140-6736(20)30183-5

Hu, T., Li, G., Zuo, Y. \& Zhou, X. (2007). Risk of hepatitis $B$ virus transmission via dental hand pieces and evaluation of an anti-suction device for prevention of transmission. Infect. Control Hosp. Epidemiol, 28(1), 80-82. https://doi.org/10.1086/510808

Kampf, G., Todt, D., Pfaender, S. \& Steinmann, E. (2020). Persistence of corona viruses on inanimate surfaces and its inactivation with biocidal agents. J. Hosp. Infect., 104(3), 246-251.

https://doi.org/10.1016/j.jhin.2020.01.022

Lei, C. et al. (2020). Potent neutralization of 2019 novel coronavirus by recombinant ACE2-Ig. Preprint at https://www.biorxiv.org/content/10.1101/2020.02.01 $.929976 \mathrm{v} 2$

Li, Q. et al. (2020). Early transmission dynamics in Wuhan, China, of novel coronavirus-infected pneumonia. $N$. Engl. J. Med., 382(13), 1199-1207. https://doi.org/10.1056/NEJMoa2001316

Li, F. (2016). Structure, function, and evolution of coronavirus spike proteins. Annu. Rev.Virol. 3, 237-261.

https://doi.org/10.1146/annurev-virology-110615042301

Liu, L. et al. (2011). Epithelial cells lining salivary gland ducts are early target cells of severe acute respiratory syndrome coronavirus infection in the upper respiratory tracts of rhesus macaques. J. Virol. 85(8), 4025-4030. https://doi.org/10.1128/JVI.02292-10

Liu, P., Chen, W. \& Chen, J. P. (2019). Viral metagenomics revealed sendai virus and coronavirus infection of malayan pangolins (Manisjavanica). Viruses, 11(11), 979. https://doi.org/10.3390/v11110979

Liu, T. et al. (2020). Transmission dynamics of 2019 novel coronavirus (2019-nCoV). The Lancet. Available at SSRN:

https://papers.ssrn.com/sol3/papers.cfm?abstract_ $\mathrm{id}=3526307$ 
Lu, C. W., Liu, X. F. \& Jia, Z. F. (2020). 2019-nCoV transmission through the ocular surface must not be ignored. The Lancet, 395, 39.

https://doi.org/10.1016/S0140-6736(20)30313-5

Nakagawa, K., Lokugamage, K. G. \& Makino, S. (2016). Chapter Five - Viral and Cellular mRNA Translation in Coronavirus-Infected Cells. Advances in Virus Research, 96, 165-192.

https://doi.org/10.1016/bs.aivir.2016.08.001

Otter, J. A. et al. (2016). Transmission of SARS and MERS corona viruses and influenza virus in healthcare settings: the possible role of dry surface contamination. J. Hosp. Infect. 92(3), 235-250. https://doi.org/10.1016/j.jhin.2015.08.027

Perlman, S. \& Netland, J. (2009). Coronaviruses postSARS: update on replication and pathogenesis. Nat. Rev. Microbiol. 7, 439-450. https://doi.org/10.1038/nrmicro2147

Rodriguez-Morales, A. J., MacGregor, K., Kanagarajah, S., Patel, D. \& Schlagenhauf, P. (2020). Going global Travel and the 2019 novel coronavirus. Travel. Med. Infect. Dis., 33, 101578.

https://doi.org/10.1016/j.tmaid.2020.101578

Rothe, C. et al. (2020). Transmission of 2019-nCoV infection from an asymptomatic contact in Germany. N. Engl. J. Med., 382, 970-971. https://doi.org/10.1056/NEJMc2001468

Seto, W. H. et al. (2003). Effectiveness of precautions against droplets and contact inprevention of nosocomial transmission of severe acute respiratory syndrome (SARS). Lancet, 361(9368), 1519-1520. https://doi.org/10.1016/S0140-6736(03)13168-6

Song, Z. et al. (2019). From SARS to MERS, thrusting coronaviruses into the spotlight. Viruses, 11(1), 59. https://doi.org/10.3390/v11010059

Samaranayake, L. P. \& Peiris, M. (2004). Severe acute respiratory syndrome and dentistry: a retrospective view. J. Am. Dent. Assoc., 1359(9), 1292-1302. https://doi.org/10.14219/jada.archive.2004.0405

Samaranayake, L. P., Reid, J. \& Evans, D. (1989). The efficacy of rubber dam isolation in reducing atmospheric bacterial contamination. ASDC J. Dent. Child, 56, 442-444.

The Lancet, (2013). MERS-CoV: a global challenge. Lancet, 381(9882), 1960

https://doi.org/10.1016/S0140-6736(13)61184-8

The Novel Coronavirus Pneumonia Emergency Response Epidemiology Team (2020). The epidemiological characteristics of an outbreak of 2019 novel corona virus diseases (COVID-19) in China. Chinese Journal of Epidemiology, 41, 145-151.

Tian, X. et al. (2020). Potent binding of 2019 novel coronavirus spike protein by a SARS coronavirusspecific human monoclonal antibody. Emerg. Microbes. Infect. 9, 382-385. https://doi.org/10.1080/22221751.2020.1729069

To, K. K. W. et al. (2020). Consistent detection of 2019 novel coronavirus in saliva. Clin. Infect. Diseases. https://doi.org/10.1093/cid/ciaa149

Wahba, L. et al. (2020). Identification of a pangolin niche for a 2019-nCoV-like coronavirus through an extensive meta-metagenomic search. Preprint at https://www.biorxiv.org/content/10.1101/2020.02.08 $.939660 \mathrm{v} 2$

Wan, Y., Shang, J., Graham, R., Baric, R. S. \& Li, F. (2020). Receptor recognition by novel coronavirus from Wuhan: an analysis based on decade-long structural studies of SARS. J. Virol. 94(7), 1-9. https://doi.org/10.1128/JVI.00127-20

Wang, C., Horby, P. W., Hayden, F. G. \& Gao, G. F. (2020). A novel coronavirus outbreak of global health concern. Lancet, 395, 470-473. https://doi.org/10.1016/S0140-6736(20)30185-9

Wang, D. et al. (2020). Clinical characteristics of 138 hospitalized patients with 2019 novel coronavirusinfected pneumonia in Wuhan, China. JAMA, 323(11), 1061-1069. https://doi.org/10.1001/jama.2020.1585

Wax, R. S. \& Christian, M. D. (2020). Practical recommendations for critical care and anesthesiology teams caring for novel coronavirus (2019-nCoV) patients. Canadian Journal of Anesthesia/Journal canadiend'anesthésie, 67, 568-576. https://doi.org/10.1007/s12630-020-01591-x

Wei, J. \& Li, Y. (2016). Airborne spread of infectious agents in the indoor environment. Am. J. Infect. Control, 44(9), 102-108. https://doi.org/10.1016/j.ajic.2016.06.003

Weiss, S. \& Leibowitz, J. (2011). Coronavirus pathogenesis. Adv. Virus Res., 81, 85-164. https://doi.org/10.1016/B978-0-12-385885-6. 00009-2

Wrapp, D. et al. (2020). Cryo-EM structure of the 2019$\mathrm{nCoV}$ spike in the pre fusion conformation. Science, 367(6483), 1260-1263. https://doi.org/10.1126/science.abb2507

Wu, F. et al. (2020). A new coronavirus associated with human respiratory disease in China. Nature, 579, 265-269. https://doi.org/10.1038/s41586-020-2008-3 
Yin, Y. \& Wunderink, R. G. (2018). MERS, SARS and other coronaviruses as causes of pneumonia. Respirology, 23, 130-137. https://doi.org/10.1111/resp.13196

Zhao, Y. et al. (2020). Single-cell RNA expression profiling of ACE2, the putative receptor of Wuhan 2019-nCoV. Preprint at

https://www.biorxiv.org/content/10.1101/2020.01.26 $.919985 \mathrm{v} 1$
Zhou, P. et al. (2020). A pneumonia outbreak associated with a new coronavirus of probable bat origin. Nature, 579, 270-273.

https://doi.org/10.1038/s41586-020-2012-7

Zhu, N. et al. (2020). A novel coronavirus from patients with pneumonia in China, 2019. N. Engl. J. Med., 382(8), 727-733. https://doi.org/10.1056/NEJMoa2001017

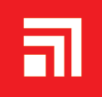 \\ CHITKARA}

\section{Journal of Multidisciplinary Research in Healthcare}

Chitkara University, Saraswati Kendra, SCO 160-161, Sector 9-C, Chandigarh, 160009, India

Volume 6, Issue 2

April 2020

ISSN 2393-8536

Copyright: [C 2020 Raj Kumar] This is an Open Access article published in Journal of Multidisciplinary Research in Healthcare (J. Multidiscip Res. Healthcare) by Chitkara University Publications. It is published with a Creative Commons Attribution- CC-BY 4.0 International License. This license permits unrestricted use, distribution, and reproduction in any medium, provided the original author and source are credited. 